\title{
Enhancement of Supermarket using Smart Trolley
}

\author{
Pranavi Satheesan \\ Dept.of Information Technology \\ Srilanka Institute of Information \\ Technology Colombo, Srilanka
}

\author{
Rajaratnam Thisanthan \\ Dept.of Information Technology \\ Srilanka Institute of Information \\ Technology Colombo, Srilanka
}

\author{
Sithivinajagamoorthy \\ Nilaxshan \\ Dept.of Information Technology \\ Srilanka Institute of Information \\ Technology Colombo, Srilanka
}

\author{
Priyanka Raveendran \\ Dept.of Information Technology \\ Srilanka Institute of Information \\ Technology Colombo, Srilanka
}

\author{
Jesuthasan Alosius \\ Dept.of Information Technology \\ Srilanka Institute of Information \\ Technology Colombo, Srilanka
}

\begin{abstract}
Electronic commerce has developed to such an extent to provide convenience, comfort and efficiency in day-to-day life. Nowadays there are a lot of stores emerging. A supermarket is a place where customers come to purchase their daily products and pay for that [1] . Lots of people spend too much time in the supermarket to purchase their goods. Because there is no proper way to pay the bills, they have no idea about present day deals / offers and people face difficulties in choosing the products from the large variety of products. The study aimed to provide a smart trolley for a supermarket which helps the customers to get benefit through the system. Techniques such as loyalty accounts, image processing, recommendation, voice assistants and person counting and payment checkout alert systems are used in order to enhance the performance of a smart trolley. Loyalty card is used to identify each customer and can be used to access the trolley. Smart trolley contains a camera and load cell which will scan the product and measure the product weight and display all the information in the LCD screen. It helps the customer to get the bill for their purchase in a flexible manner. Product recommendation system analyses customer needs and recommends best products to both new and existing customers in order to attract the customers and help them to make purchasing decisions. Voice assistants will help customers to ask queries related to locations, discounts, offers, and prices which reduce the need for a shopkeeper in the supermarket. In the billing counter, if more than five people are lined up, the system will alert the customer to be like "move a quick checkout counter" which maintains safe distance between the customers during the corona situation.
\end{abstract}

\section{Keywords}

Recommendation, Voice Assistant, Image Processing, Loyalty accounts

\section{INTRODUCTION}

Shopping mall is a place where individuals get their everyday necessities [2]. In this modern world, people always expect technology to ease their work rather than doing themselves because of their engaged life. In this inventive world, each mall and supermarkets utilize shopping trolleys to help customers to choose and purchase the items which they expect to buy. Smart trolley systems provide fast purchase and great convenience to customers. This system works only for those customers who are having the loyalty card of the supermarket. The proposed system starts to work when a customer gets into the supermarket and takes the trolley. Each trolley has its own RFID reader. The smart trolley reads the RFID card which is in the loyalty card of the customer. There is a QR scanner facility to read the QR code of the product which shows the price, weight etc. The QR scanner is working by using image processing which helps to read the QR code of the product. Therefore, customers can easily get to know the total amount and can purchase according to their budget. And also, with this there is no need for customers to wait in the queue for scanning the products for billing purposes. The customer requires downloading a mobile application. Recommendation system collects information related to what a customer has previously seen or bought, with the aim of providing personalized suggestions on unobserved items that are likely to be of interest. It analyses customer needs and suggests the best possible shopping list. Voice assistant is programmed for the customers to answer the queries that are related to the supermarket system. Voice assistants can understand what the customer is asking and provide replies in text messages to the customer. The smart trolley will reduce the efforts and time consumption of the customers. In the covid 19 panamic situation customers need to maintain the distance but customers often need to wait at the counter for their payment for a long time. Therefore in the billing counter if more than five customers lined up,the system will alert the smart trolly using customers to move a quick checkout counter. in a real time cctv camera capture and system alert in trolly display.

\section{BACKGROUND AND LITERATURE SURVEY}

\subsection{Background}

In the early days of retailing all products had to be fetched by way of an assistant from cabinets on one facet of a counter even as the clients stood on the opposite facet and pointed to what they desired [3]. Also, many foods did not come in the individually wrapped consumer-size packages taken for granted today, so an assistant had to measure out the precise amount desired by the consumer. These practices have been obviously labor-intensive and consequently quite steeply priced. The shopping process was slow, as the number of clerks employed in the store limited the number of customers who could be attended at one time.

The idea of a self-service grocery store became advanced with the aid of Clarence Saunders and his Piggly Wiggly shops. His first store opened in Memphis, Tennessee in 1916. Saunders was awarded several patents for the ideas he 
incorporated into the Piggly Wiggly stores. The stores were a financial success and Saunders began to offer franchises.

A\&P became some other successful early chain in Canada and the United States, having grown to be commonplace in North American cities within the 1920s [3].

\subsection{Literature review}

Modelling of Future Automatic Trolley System based on Sensors and Image Processing Guidance for Supermarket [2]

This paper proposes a small trolley system which provides fast purchase and great convenience to customers. The main objectives are to eliminate human labor to push trolleys and to reduce the time of the queue in supermarkets. This automatic trolley system is an intelligent system which contributes as an efficient system in shopping malls to follow humans and avoid the obstacles in the path. The proposed system starts to work when a customer gets into the mall and takes the trolley. Each trolley has its own RFID reader. So, the trolley follows the customer who has the corresponding RFID card called a customer card. The movement of the system is controlled by the ultrasonic sensor and RFID tag. The QR scanner, which uses image processing, reads the $\mathrm{QR}$ code of the product taken by the customer and displays the price and other product information.

\section{RFID Based Smart Trolley for Supermarket Automation [4]}

This paper describes the concept of an RFID reader -based trolley for supermarket automation. To make the purchase easy, the RFID reader with an electronic hardware device is equipped with a trolley. The RFID will be included in each and every product, with a unique ID number so that the product can be recognized. The RFID reader obtains information from the RFID tag about the product, and when the consumer puts the product into the trolley, the cost of the item is applied to the sales bill when the item is displayed in front of the reader, and is seen on the LCD monitor. The trolley is configured in such a way that the rack number shown on the LCD will be identified. It also has the provision to withdraw the goods from the trolley where the cost of the overall cost is deducted. After the items are added, the cost is added up and it offers a warning signal when it exceeds the certain limit to show that the customer budget has surpassed.

\begin{abstract}
Automated Smart Trolley for Supermarkets [5]
In this paper trolley has done this with a pre-built RFID reader. Such readers can read RFID tags in which the product information is present. Each product will have an RFID tag in supermarkets that holds full details about that product such as price, number, etc. In order to add and remove items, the customer can scan the product tags to the RFID reader and add the goods to the cart by switch present in the trolley. While shopping, they can edit the basket at any time. The total quantity of goods in the trolley is measured automatically and shown on display. There will be a payment system where the customer will check their tag ID and pass the payment product info. When the customer finishes shopping, they should press the shopping End button. When it is pressed, information about the purchased client is shown via Zigbee.
\end{abstract}

\section{Smart Trolley using Smart Phone and Arduino [6]}

In this paper, the RFID tag is attached to the customer's membership card which is given to their loyalty customers by the supermarket. The RFID reader is connected to a shopping trolley or shopping basket that recognizes the daily customer's presence and thus serves as a Smart Trolley. The standard client allows a mobile application to be downloaded and then the handset functions as a barcode scanner. The barcode that is sent to Arduino through the Bluetooth module is created with the aid of a barcode scanner. When the user has finished shopping the user clicks the button on the trolley and the information shown on the LCD is transferred to the computer. This is done by using NRF24L01 which is a serial peripheral interface and using this the data will be transferred from the trolley to the computer at the billing counter.

Smart Cart with Automatic billing, product details, product Recommendation with Anti-Theft using RFID \& Zigbee [1]

The purpose of this paper is to use RFID and ZigBee communication to provide a centralized and automated billing system. Supermarkets will be provided with an RFID tag for each product to identify its type. There is a PID (Product Identification Device) in each cart. Microcontroller, LCD, RFID reader, EEPROM, and a ZigBee module are included in the PID. There will also be a centralized database from which we can give product recommendations to the customer. The centralized database will give product recommendations and information about the product on the LCD screen present on the shopping cart, which will help the customer in buying products.

\section{Number of passing people using stereo camera [9]}

Terada [9] proposed a counting method which segmented the human region and road region by using the three-dimensional data obtained from a stereo camera. However, this system also assumed only simple movement of pedestrians.

In this paper, we propose a real-time people counting system with a single camera for security inside the building. The camera is hung from the ceiling of the gate so that the image data of the passing people are not fully overlapped. The implemented system recognizes people movement along various directions. To track people even when their images are partially overlapped, the proposed system estimates and tracks a bounding box closing each person in the tracking region

\section{RESEARCH GAP}

Table 1. Table captions should be placed above the table

\begin{tabular}{|c|c|c|c|c|c|c|c|}
\hline & $\begin{array}{c}\text { Onli } \\
\text { ne } \\
\text { Pay } \\
\text { men } \\
\text { t }\end{array}$ & $\begin{array}{c}\text { Loy } \\
\text { alty } \\
\text { Prog } \\
\text { ram }\end{array}$ & $\begin{array}{c}\text { Wei } \\
\text { ght } \\
\text { Sens } \\
\text { or }\end{array}$ & $\begin{array}{l}\text { Dete } \\
\text { ct } \\
\text { Prod } \\
\text { uct } \\
\text { Ima } \\
\text { ge }\end{array}$ & $\begin{array}{c}\text { Rec } \\
\text { om } \\
\text { men } \\
\text { dati } \\
\text { on }\end{array}$ & $\begin{array}{c}\text { Voic } \\
\mathrm{e} \\
\text { Assi } \\
\text { stant }\end{array}$ & $\begin{array}{c}\text { Perso } \\
\text { n } \\
\text { counti } \\
\text { ng }\end{array}$ \\
\hline $\begin{array}{l}\text { Smart Cart with } \\
\text { Automatic } \\
\text { Billing, Product } \\
\text { Information, } \\
\text { Product } \\
\text { Recommendation } \\
\text { Using RFID \& } \\
\text { Zigbee with } \\
\text { Anti-Theft [1] }\end{array}$ & 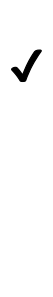 & & & $\sqrt{ }$ & $\sqrt{ }$ & & \\
\hline
\end{tabular}




\begin{tabular}{|c|c|c|c|c|c|c|}
\hline $\begin{array}{l}\text { Modelling of } \\
\text { Future Automatic } \\
\text { Trolley System } \\
\text { based on Sensors } \\
\text { and Image } \\
\text { Processing } \\
\text { Guidance for } \\
\text { Supermarket [2] }\end{array}$ & $\sqrt{ }$ & $\checkmark$ & & $\sqrt{ }$ & & \\
\hline $\begin{array}{c}\text { Smart Trolley } \\
\text { using Smart } \\
\text { Phone and } \\
\text { Arduino [6] }\end{array}$ & $\sqrt{ }$ & $\sqrt{ }$ & & $\sqrt{ }$ & & \\
\hline $\begin{array}{l}\text { Smart Trolley in } \\
\text { Mega Mall [7] }\end{array}$ & $\boldsymbol{V}$ & & & $\sqrt{ }$ & & \\
\hline $\begin{array}{l}\text { Automated Smart } \\
\text { Trolley for } \\
\text { Supermarkets [5] }\end{array}$ & $\sqrt{ }$ & & & $\sqrt{ }$ & & $\sqrt{ }$ \\
\hline $\begin{array}{l}\text { Smart Trolley } \\
\text { using IOT [8] }\end{array}$ & $\sqrt{ }$ & & & $\boldsymbol{V}$ & & \\
\hline $\begin{array}{l}\text { RFID Based } \\
\text { Smart Trolley for } \\
\text { Supermarket } \\
\text { Automation [4] }\end{array}$ & $\sqrt{ }$ & & & $\sqrt{ }$ & & \\
\hline The research & $\sqrt{ }$ & $\sqrt{ }$ & $\sqrt{ }$ & $\sqrt{ }$ & $\sqrt{ }$ & $\sqrt{ }$ \\
\hline
\end{tabular}

\section{METHODOLOGY}

This chapter explains about the methodology we intend to adopt to achieve the overall aim of proposing effective mechanisms to develop a smart trolley for supermarkets.

The proposed mechanism will be carried out by utilizing the four components effectively.

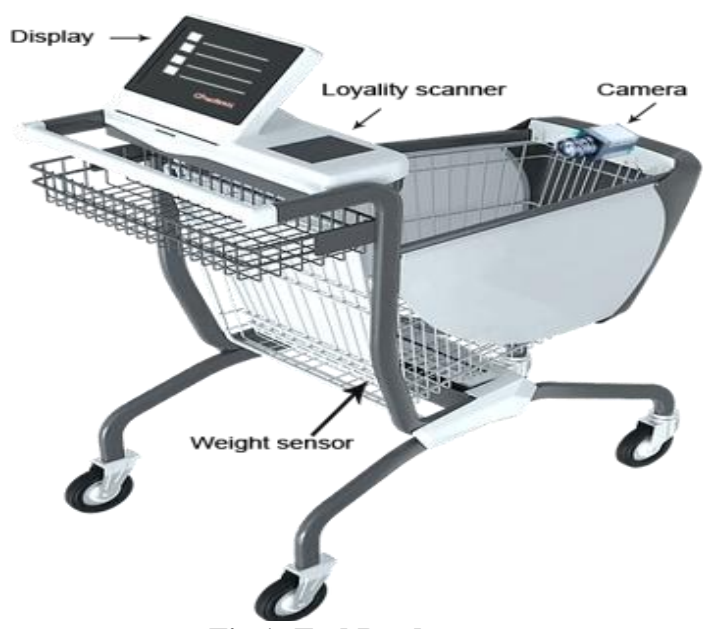

Fig 1: End Product
Figure 1 shows the smart trolley which is designed with additional features compared with the usual trolley in all supermarkets. This Smart trolley includes a camera with ultrasonic sensor, weight scanner, RFID reader, microphone and LCD display. All loyalty customers are provided with the loyalty card which is a RFID card. Additionally, we CCTV cameras were placed near the billing counter. When a customer shows the loyalty card (RFID card) near the trolley RFID reader, it will find the loyalty customer details and then the customer can access the trolley. Here, RFID readers will get the card access and send it to the microcontroller. The microcontroller sends the information of the card to the transceiver, which then sends it to the server. The server then collects the necessary information and, using the same transceiver, sends it back to the microcontroller.

Customers can easily scan the products to buy and the trolley displays all the information related to the product in the display (weight, quantity and price). Customer has to place the product near the camera which is located in the trolley to scan products before placing the product inside the trolley. Camera will automatically take the image of the product. The image of the product will be checked with the image already stored in the database using the OpenCV BFMatcher method. Weight is measured by a weight sensor which is fitted on the trolley when the customer scans the items to be purchased and placed inside the trolley. Weight sensor is used to match the measured weight with the actual weight to avoid abnormal activities. Each time when the products are placed inside the trolley the product's weight is checked. If a customer wants to return the product which is purchased and put inside the trolley, he/she just has to scan the product again, the product picture will be taken to confirm the intended product from the smart trolley and remove them from the system. If scanning is successful the product information is shown on the LCD monitor, the microcontroller shows billing information. At that time the system provides the best recommendation list to the customer which helps the customer to purchase the product if they actually want it. The product recommendation system comprises two levels. The first level recommendation is before choosing a product and the second level of recommendation is after choosing a product. First of all, data of previous searches need to be collected. Recommendation system recommends products that are closely related with customer's preferences. Products are recommended to the customers using the item-based method which finds the similarity of different items using cosine similarity. In the second level it recommends associated products using association rule mining in order to complete the buying process. The system recommends the most popular products to the new customers who lack purchasing history.

While purchasing the products, customers can ask queries using a microphone, then the system will pop up the answer in the LCD screen. Speech recognition allows the elderly and the physically impaired to interact with state-of-the-art products and services quickly and naturally from the implemented system which will be displayed through the LCD screen. Certain code words will be already fed up in the system, when the customers ask a question, if those words are missing, the synonyms will be understood by the system. Voice assistant will check the queries with the questions and answers corpus. Natural language processing is used to find the similarity among texts and then the answer will be displayed to the customer. This part will focus on introducing sentence embedding's and how it can be used in building QA systems.

In the billing counter, if more than 5 people are lined up, the 
system will alert the customers to move the Quick checkout counter. The number of customers lined up in the bill counter is found using object tracking mechanism through the CCTV camera. Vision-based real-time people counting comprise all techniques which are able to extract the number of people who are present in an observed area. Object tracking in a live video sequence is the process of finding the same object in a different frame. It uses the different facility to previously extract by the correct segmentation model. Motion model is used in real live video.

\section{RESULTS AND DISCUSSIONS}

\subsection{Result}

Smart Trolley aims to function as a small self- checkout system that provides users with adaptive capabilities to make easy transactions in the supermarket. This would be exceptionally effective and should be fully synchronized with the current structure of the supermarket. Figure 2 shows the final product of the smart trolley.

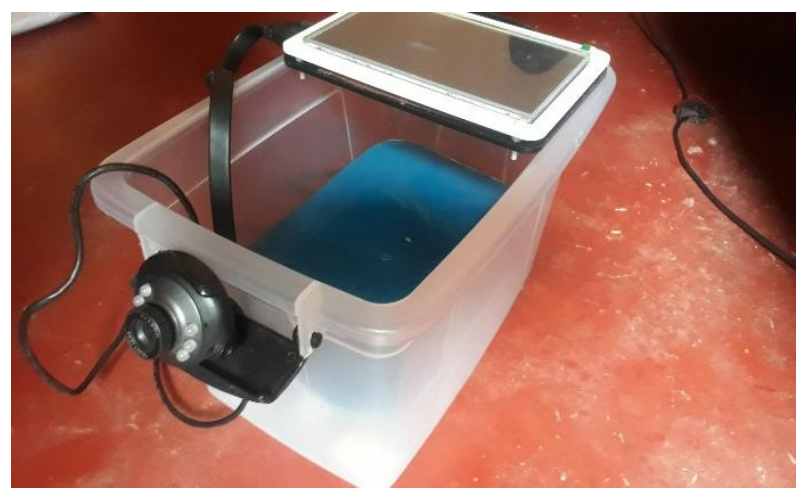

Fig 2: Final Product of smart trolley system

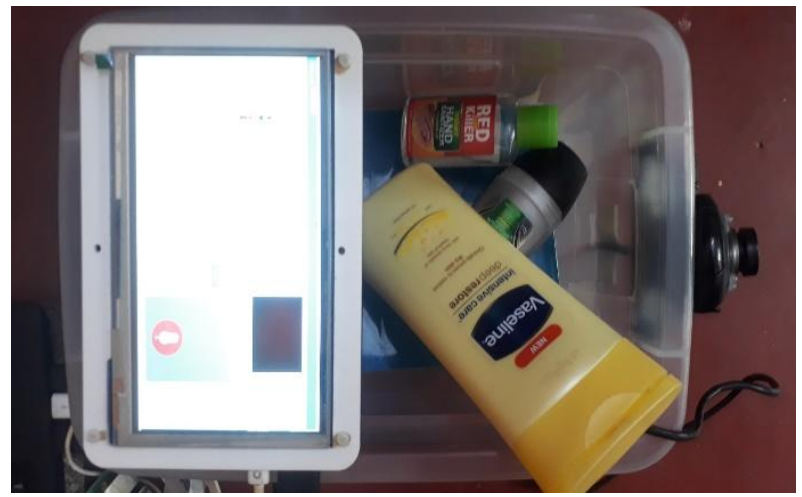

Fig 3: Smart trolley with User Interface

Figure 3 shows the user interface of the smart trolley which the customers interact to purchase the products.

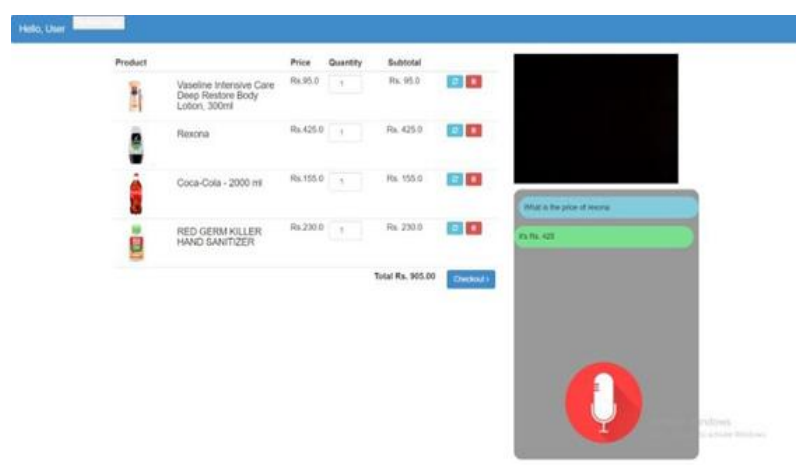

\section{Fig 4: Integrated User Interface}

Figure 4 shows the products that are added into the trolley and also it shows the voice assistant that people can use to ask queries. Voice recognition has been done in speech and must be converted from physical sound to an electrical signal with a microphone, and then to digital data with an analog-to-digital converter. Once digitized, models can be used to transcribe the audio to text which was done using a speech recognition python library. Text recognition sentence embedding is done with Facebook infer sent model which embeds a full sentence into a vector space.

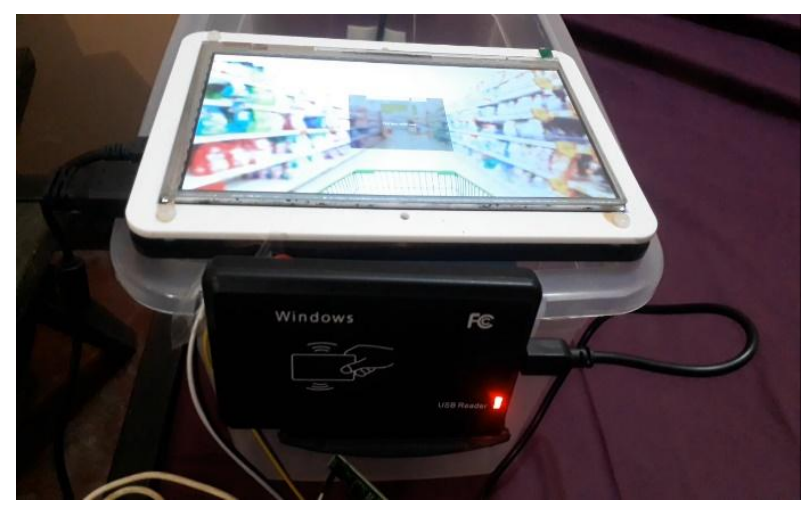

Fig 5: Smart Trolley with RFID loyalty cart system

Figure 5 shows that Customer can access the trolley by using the RFID card. Each RFID card have sperate digital number. We use that RFID number as a primary key.

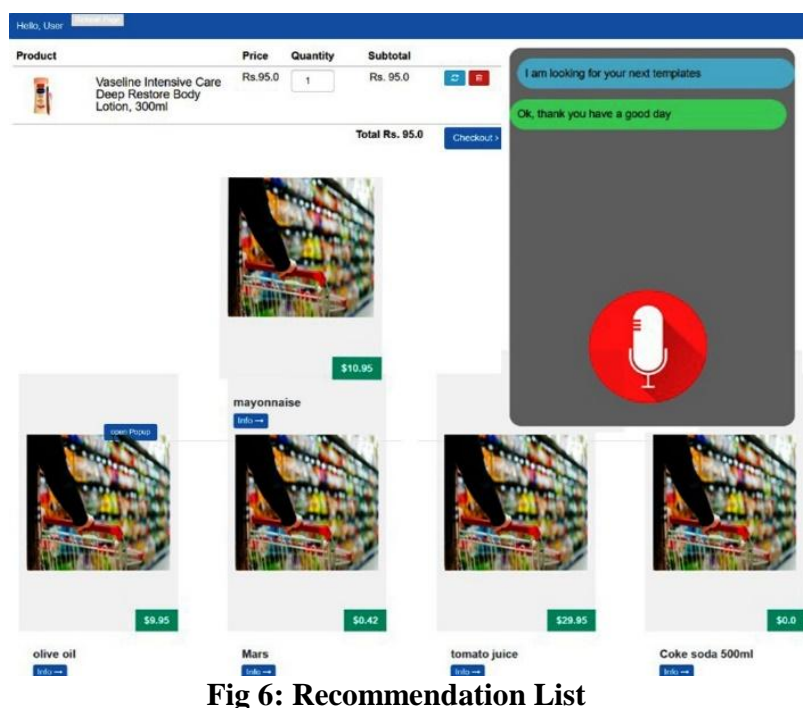

Figure 6 shows that if a customer scans the product, the system recommends associated products for the scanned product. It is done using the item-based method which finds the similarity between items 


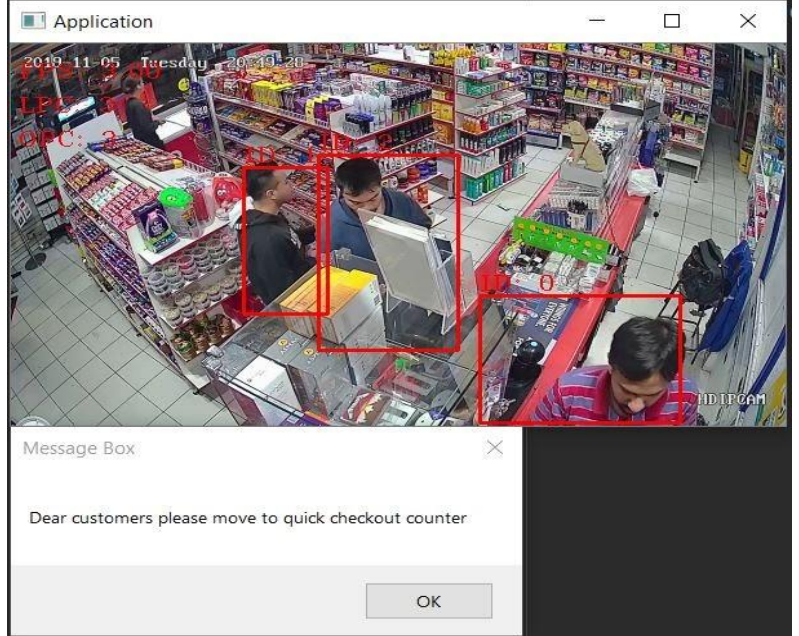

Fig 7: Person counting and alert the customer

Figure 7 shows that how person counting can be done. If more than 5 customers waiting for the billing in the counter its alert to move to the quick checkout counter.

\subsection{User Evaluation}

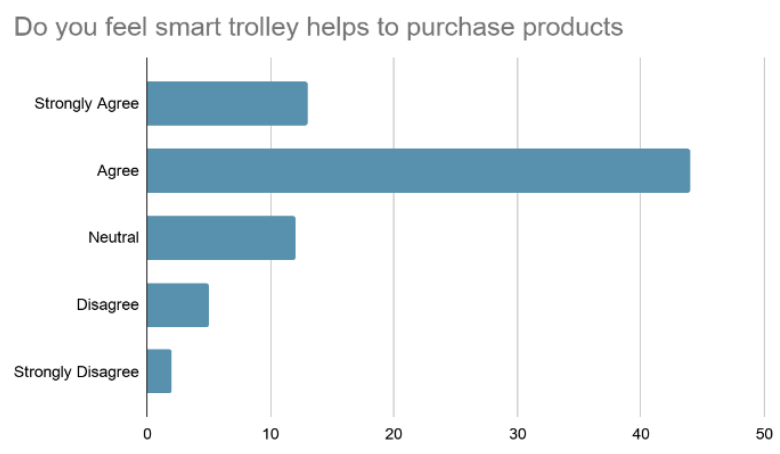

Fig 8: Bar chart of whether smart trolley helps to purchase products

Figure 8 shows that out of 76 people most people agree that smart trolley helps to purchase the products. Least people strongly disagree that smart trolleys help to purchase products. Therefore, it clearly states product recommendation helps the customers to purchase the products.

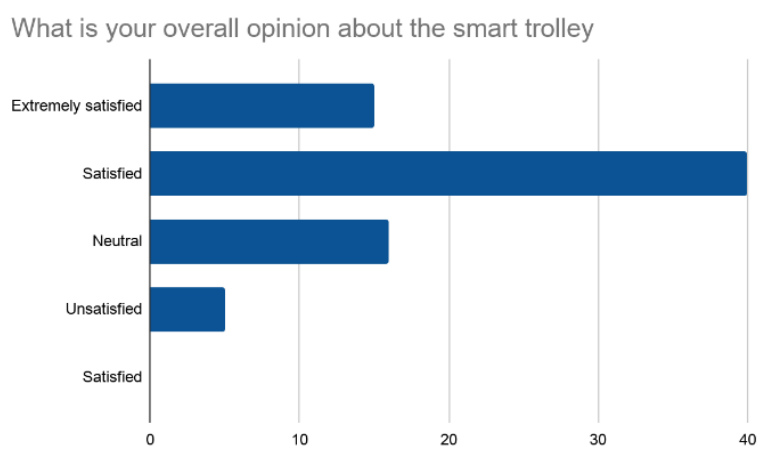

Fig 9: Bar chart of overall opinion about the smart trolley

Figure 9 shows that most people are satisfied with the smart people. Least people unsatisfied with the smart trolley. Therefore, it concludes people are satisfied with the smart trolley

\section{CONCLUSION}

Taking into account the changing trend in supermarkets, the proposed smart trolley is designed. Smart trolley makes the billing of goods in an efficient, easier and fast way. Each product in the shop or a mall will have an RFID tag on it. Depending upon the customer buying habits the system gives discounts for the customers. System displays the number of products in trolley and total cost of the products on the LCD screen by using image processing. It will also provide antitheft system for a supermarket with the help of the weight sensor which matches the weight displayed on the screen with the weight calculated by the weight sensor. System recommends personalized items in order to eliminate inconveniences arising from delay and confusion to choose their desired product among different kinds of products with the nearest standard. Voice assistant is built in the trolley in order to help the customers to know about deals/offers in the supermarket and ask the queries using the microphone. Overall idea of smart trolleys is to make shopping effortless, hassle free and easy for the customers.

\section{ACKNOWLEDGMENT}

First of all, we want to thank our research supervisor Mr. Jesuthasan Alosius for his support which make this research success. Our Sincere thanks to our co-supervisor, Janani Tharmaseelan who shares her knowledge and motivated us during this research.

\section{REFERENCES}

[1] F. A. Yewatkara, "Smart Cart with Automatic Billing,Product Recommendation Using RFID \& Zigbee with Anti-Theft," 7th International Conference on Communication, Computing and Virtualization 2016, pp. 793-800, 2016.

[2] A. T. M, "Modelling of future Automatic Trolley System based on Sensors and Image Processing Guidance for supermarket," 3Department of Electronic and Electronics Engineering, 2019.

[3] "New World Encyclopedia," [Online]. Available: https://www.newworldencyclopedia.org/entry/Supermark et. [Accessed February 2020].

[4] A. P. A. G. A. K. M. M. J. ANJALIPERADATH, "RFID Based Smart Trolley for Supermarket Automation," International Research Journal of Engineering and Technology (IRJET), vol. 4, 2017.

[5] H.K.Sivaraman, "Automated Smart Trolley for Supermarkets," International Journal of Engineering Research \& Technology (IJERT), vol. 6, 2018.

[6] N. G. S. K. a. A. G. H. S. Bedi, "Smart Trolley using Smart Phone and Arduino," Journal of Electrical \& Electronic Systems, vol. 6, 2017.

[7] S.J.S.Awati, "Smart Trolley in Mega Mall," International Journal of Emerging Technology and Advanced Engineering, vol. 2, 2012.

[8] G. P. K. G. S. Nitnaware, "Smart Trolley using IOT," International Journal for Research in Applied Science \& Engineering Technology (IJRASET), vol. 5, 2017.

[9] D. K.Terada, "Accounting method of the number of passing people using a stereo camera," 1999. 